\title{
Gas exchange responses to constant work rate exercise in chronic cardiac failure
}

\author{
M Riley, J Pórszász, C F Stanford, D P Nicholls
}

\begin{abstract}
Objective-To examine the time course of changes in minute oxygen consumption and other gas exchange variables and heart rate during constant work rate exercise in patients with chronic cardiac failure.

Design-Treadmill exercise with on line measurement of gas exchange and a target duration of 10 minutes.

Subjects-Seven men in New York Heart Association class II, six in class III, and seven controls.

Main outcome measures-Gas exchange variables and heart rate were averaged for the final two minutes of exercise. Time constants were calculated for the increase in all variables.

Results-Consumption of oxygen at the end of exercise $\left(\mathrm{VO}_{2}\right)$ was similar in class II patients (mean $(95 \%$ confidence interval $\left(95 \%\right.$ CI) $14.9(13.6$ to $16 \cdot 1) \mathrm{ml} \mathrm{kg}^{-1}$ min $\left.^{-1}\right)$, class III patients $(13 \cdot 2(11.2$ to 15.1) $\left.\mathrm{ml} \mathrm{kg}^{-1} \mathrm{~min}^{-1}\right)$, and controls (13.3 (12.5 to $\left.14 \cdot 2) \mathrm{ml} \mathrm{kg}^{-1} \mathrm{~min}^{-1}\right)$. The patients reached this $\mathrm{Vo}_{2}$ more slowly with longer exponential time constants of $0.82(0.59$ to $1.04) \mathrm{min}$ in class II and $1.19(0.86$ to 1.51$)$ min in class III, than the $0.49(0.35$ to $0.64) \mathrm{min}$ in the controls. Time constants of other gas exchange variables and heart rate were also longer in patients. By analysis of covariance, peak $\dot{\mathrm{VO}}_{2}$ accounted for the between group difference in the time constant for $\dot{V O}_{2}$, suggesting that circulatory factors may be an important cause of the delayed kinetics. Conclusions-A delayed rise in $\mathrm{Vo}_{2}$ in response to exercise may be responsible for subnormal values of $\mathrm{VO}_{2}$ early in exercise in patients with chronic cardiac failure.
\end{abstract}

(Br Heart F 1994;72:150-155)

Royal Victoria

Hospital, Belfast, Northern Ireland $M$ Riley

C F Stanford

D P Nicholls

Institute of

Pathophysiology,

Medical University of

Medical Univers

J Pórszász

Correspondence to:

Dr D P Nicholls, Royal

Dr D P Nicholls, Royal

Victoria Hospital, Belfa BT12 6BA, Northern Ireland.

Accepted for publication 26 January 1994

Patients with chronic cardiac failure characteristically have a reduced maximal exercise capacity and hence a diminished oxygen consumption $\left(\mathrm{VO}_{2}\right)$ at peak exercise. Also, some investigators have shown that $\dot{\mathrm{VO}}_{2}$ during incremental work rate protocols is lower in patients with chronic cardiac failure than in controls, when compared at similar absolute work intensities. This occurs during both treadmill ${ }^{1-3}$ and cycle ergometer ${ }^{4}$ incremental exercise tests, with the duration of exercise stages ranging from one to six minutes. The discrepancy in $\dot{\mathrm{VO}}_{2}$ is more pronounced in severely ill patients. ${ }^{2}$

These findings are interesting as $\mathrm{VO}_{2}$ at steady state is closely dependent on the work rate being performed. ${ }^{5}$ The implication is either that there exists a basic abnormality in muscle metabolism in chronic cardiac failure, which leads to abnormal muscle bioenergetics, ${ }^{46}$ or alternatively that the attainment of steady state conditions is simply delayed compared with normal. ${ }^{1}$ Meakins and Long found a slow rate of rise in $\mathrm{VO}_{2}$ in one patient with rheumatic heart disease when walking at the same speed as a control subject, although they did not resolve the question as to whether or not the patient's $\mathrm{VO}_{2}$ eventually reached that of the control.

We hypothesised that the eventual $\mathrm{VO}_{2}$ is not different when patients with chronic cardiac failure and normal controls perform equal absolute work rates, but rather that in patients there is a slowing of the rate at which this $\dot{\mathrm{VO}}_{2}$ is approached. To test this hypothesis, we used a constant work rate exercise test of 10 minutes in duration, and examined the time course of the resultant changes in gas exchange variables and heart rate.

\section{Patients and methods}

PATIENTS

Thirteen men (mean age 64 (range 48-76) with compensated chronic cardiac failure took part in the study. Seven patients were in New York Heart Association (NYHA) class II and six in class III. The mean time from diagnosis was $15 \cdot 1$ (range 3-27) months. All had been clinically stable for a minimum of two months before the study. Mean body weight was 67 (range 49-91) $\mathrm{kg}$. The mean left ventricular ejection fraction as determined by radionuclide angiography was 0.28 (range $0.09-0.43$ ), and the cardiothoracic ratio was $>0.50$ in all cases. The aetiology of chronic cardiac failure was ischaemic heart disease in 12 and alcoholic cardiomyopathy in one. Three patients were in atrial fibrillation, and 10 in sinus rhythm. All patients were being treated with diuretics (median dose 80 (range 40-120) $\mathrm{mg}$ frusemide) and four with digoxin. Also three patients were taking flosequinan (Manoplax, Boots UK) and four were taking captopril. None had significant pulmonary disease (from history or spirometry, defined as forced expiratory volume in one vital capacity) $<75 \%$ predicted), intermittent claudication, or musculoskeletal disease that second $\left(\mathrm{FEV}_{1}\right)<75 \%$ or $\mathrm{FEV}_{1} / \mathrm{FVC}$ (forced 
could lead to a premature end of exercise. Clinical evidence of fluid overload (peripheral oedema, raised venous pressure, basal râles) was absent at the time of the study.

\section{CONTROLS}

Seven men (mean age 63.4 (range 56-67) with no cardiac or pulmonary disease acted as controls. They were healthy on the basis of normal history, examination, and exercise testing. All were sedentary and were taking no medication. Body weight was 81 (range 68-101) kg.

The Ethics Committee of The Queen's University of Belfast granted approval for the study. All the men gave informed consent.

\section{PROTOCOL}

Before the study all men were familiarised with the apparatus; all patients had performed at least three and controls at least two previous incremental treadmill exercise tests. Data from our laboratory suggest that, at least in the case of maximal exercise tests, one familiarisation test is adequate. ${ }^{8}$ Patients and controls then returned to the laboratory on two separate occasions. On the first occasion a symptom limited maximal graded treadmill test was performed for determination of peak $\mathrm{VO}_{2}$. On the second day patients and controls went to the laboratory one to two hours after a light breakfast or light lunch. A teflon cannula was inserted into an antecubital vein and they rested supine for 10 minutes. After two minutes standing on the treadmill, a constant work rate treadmill test with on line measurement of respired gas analysis was carried out. Treadmill grade was $5 \%$ and speed was $2 \cdot 7$ $\mathrm{km} \mathrm{h}^{-1}$ in all tests. The patients and controls were asked not to grip the treadmill bars. The test ended after 10 minutes, or earlier if the patients could not tolerate the full 10 minutes. A blood sample for lactate was taken immediately before the end of exercise. The electrocardiogram was monitored continuously in CM5 configuration, and blood pressure was recorded at three minute intervals with a mercury sphygmomanometer. Patients and controls were asked to indicate their perceived level of exertion at the end of exercise by means of a Borg score. ${ }^{9}$

\section{MEASUREMENT OF GAS EXCHANGE}

Minute ventilation (VE) was measured with a vane turbine placed on the inspiratory side of a non-rebreathing respiratory valve circuit (dead space $88 \mathrm{ml}$ ) in conjunction with a ventilometer (PK Morgan, UK). Interruptions of a light beam by the vane were counted to measure inspired volume that was then converted to expired volume with the Haldane correction and standard formulae. Expired gas was led through lightweight tubing into a five litre mixing chamber. This was sampled continuously and expired $\mathrm{O}_{2}$ and $\mathrm{CO}_{2}$ concentrations determined by paramagnetic and infrared analysis respectively. The outputs from the ventilometer and gas analysers were fed through an analog to digital converter to an Ericsson microcomputer for on line calcula- tion of $\dot{\mathrm{VO}}_{2}, \mathrm{CO}_{2}$ production $\left(\mathrm{V} \mathrm{CO}_{2}\right)$, and $\dot{\mathrm{VE}}$. Data points were averages of 15 second periods. Calibration of the ventilometer was carried out weekly with multiple strokes of a standard one litre syringe, and the gas analysers were calibrated before each test with gases of known concentration. Validation of the system has been previously described. ${ }^{10}$

\section{BLOOD SAMPLING AND ASSAY}

Lactate samples were precipitated immediately in $8 \%$ perchloric acid and the supernatant assayed by an enzymatic colourimetric method (Sigma, St Louis, MO, USA). The coefficient of variation for the assay was $0 \cdot 8 \%$.

\section{STATISTICAL METHODS}

Differences among groups were assessed by analysis of variance and between group comparisons were made with $t$ tests with Bonferroni's correction. The relation between variables was described by simple correlation. The degree to which differences between the groups could be explained by confounding variables was determined, where appropriate, by performing an analysis of covariance. A P value $<0.05$ was taken as the level of significance.

CURVE FITTING FOR THE EXERCISE RESPONSES After initial visual inspection, the $15 \mathrm{~s}$ averaged gas exchange data were fitted to a single compartment exponential "wash-in" model of the type:

$$
\mathrm{f}(t)=\mathrm{A}-\mathrm{Be}^{-\mathrm{t} / \tau},
$$

where $f(t)$ represents the value of $\dot{V O}_{2}, \dot{V}_{\mathrm{CO}_{2}}$, $\dot{\mathrm{VE}}$, or heart rate after $t$ minutes of exercise, A represents the asymptotic value to which the function rises, $B$ represents the total increment from baseline to the asymptote, and $\tau$ is the time constant. The longer the time constant, the slower are the kinetics of the physiological variable under consideration. The Sigmaplot graphics package (Jandel Scientific, Corte Madera, CA, USA) was used to select values for $\mathbf{A}, \mathbf{B}$, and $\tau$ by multiple iterations so as to achieve a minimum residual sum of squares.

\section{Results}

INCREMENTAL EXERCISE

Peak $\dot{\mathrm{VO}}_{2}$ during symptom limited maximal exercise was much greater in controls (mean ( $95 \%$ confidence interval (95\% CI)) 29.7 $(25.7$ to 33.6$\left.) \mathrm{ml} \mathrm{kg}^{-1} \mathrm{~min}^{-1}\right)$ than in patients with either NYHA class II $(21.6(19.4$ to $23 \cdot 8)$ or class III symptoms $(15 \cdot 1$ $(13 \cdot 6-16 \cdot 7) \mathrm{ml} \mathrm{kg}^{-1} \mathrm{~min}^{-1}$.

\section{CONSTANT WORK RATE EXERCISE}

Although no adverse events occurred during constant work rate exercise, three patients with class III symptoms were unable to complete the full 10 minutes of the test because of leg fatigue. All patients and controls completed at least six minutes. Table 1 shows the treadmill time, Borg score of perceived exertion, the lactate value and its increment from 
Table 1 Variables at the end of the exercise period

\begin{tabular}{|c|c|c|c|c|}
\hline & \multicolumn{2}{|l|}{ Patients } & \multirow[b]{2}{*}{ Controls } & \multirow{2}{*}{$\begin{array}{l}\text { Pvalue } \\
(\text { ANOVA })\end{array}$} \\
\hline & $N Y H A$ class $I I$ & NYHA class III & & \\
\hline Treadmill time (min) & 10 & $8 \cdot 3(6 \cdot 1$ to $10 \cdot 0)$ & 10 & \\
\hline Borg score & $2.9(1.5$ to 4.2$)$ & $3.5(2.4 \text { to } 4.6)^{\star \star}$ & $1.4(0.3$ to 2.4$)$ & $<0.02$ \\
\hline Lactate $(\mathrm{mM})$ & $1.46(1.03$ to 1.88$)$ & $2.06(1.68 \text { to } 2.43)^{\star \star \star}$ & $1.15(0.87$ to 1.42$)$ & $<0.002$ \\
\hline $\mathrm{Vo}_{2}\left(\mathrm{ml} \mathrm{kg}^{-1} \mathrm{~min}^{-1}\right)$ & $14.9(13.6$ to 16.1$)$ & $13.2(11.2$ to 15.1$)$ & $13.3(12.5$ to 14.2$)$ & $0 \cdot 1$ \\
\hline $\mathrm{VCO}_{2}\left(\mathrm{ml} \mathrm{kg} \mathbf{~ k i n}^{-1}\right)$ & $13 \cdot 2(12 \cdot 1 \text { to } 14 \cdot 2)^{\star \star \star}$ & $12.8(11.5 \text { to } 14.1)^{\star}$ & $11.1(10.5$ to 11.8$)$ & $<0.005$ \\
\hline $\operatorname{VE}\left(\mathrm{Lmin}^{-1}\right)$ & $33.0(25.3$ to 40.6$)$ & $37.9(33.5 \text { to } 42.2)^{\star \star}$ & $27.9(22.9$ to 33.0$)$ & $<0.0001$ \\
\hline $\mathbf{R}$ & $0.89(0.85 \text { to } 0.92)^{\star}$ & $0.97(0.89 \text { to } 1.06)^{\star \star \star}$ & $0.84(0.81$ to 0.87$)$ & $<0.001$ \\
\hline Heart rate (beats $\mathrm{min}^{-1}$ ) & $121 \cdot 0(102 \text { to } 140)^{\star}$ & $127 \cdot 0(113 \text { to } 141)^{\star \star \star}$ & $99 \cdot 4(89$ to 110$)$ & $<0.02$ \\
\hline
\end{tabular}

${ }^{\star} \mathrm{P}<0.05 ;{ }^{\star \star} \mathrm{P}<0.01 ;{ }^{\star \star \star} \mathrm{P}<0.005$, Bonferroni correction, compared with controls. Gas exchange measurements and heart rate averaged over the final two minutes of exercise. Values are mean $(95 \% \mathrm{CI})$, except treadmill time, which is median (range). $R$, respiratory exchange ratio.

rest at the end of exercise, the average $\mathrm{VO}_{2}$, $\mathrm{VCO}_{2}, \mathbf{R}$ (respiratory exchange ratio, $\left.\dot{\mathrm{V}} \mathrm{CO}_{2} / \mathrm{VO}_{2}\right)$, and heart rate for the final two minutes of exercise. Perceived exertion was greater in patients, as were lactate, $\mathrm{VCO}_{2}, \mathrm{R}$, and heart rate. Differences were more pronounced in the class III group. By contrast $\dot{\mathrm{VO}}_{2}$ was not significantly different between patients and controls. In patients taken as a single group, peak $\mathrm{VO}_{2}$ was inversely correlated with lactate at the end of exercise $(r=$ $0.65, \mathrm{P}<0.02)$ and $\mathrm{R}(r=0.72, \mathrm{P}<0.01)$.

Figure 1 shows the average responses of $\dot{\mathrm{VO}}_{2}, \dot{\mathrm{V}} \mathrm{CO}_{2}, \dot{\mathrm{VE}}$, and heart rate for the two patient groups and the controls. Repeated measures analysis of variance was performed for the first six minutes of exercise, the period for which complete data for all subjects were available. The $\mathrm{VO}_{2}$ displayed a time depen-

Figure 1 Time courses of the average $(A) \mathrm{VO}_{2}$ (B) $\mathrm{VCO}_{2}$, (C) $V E$, and (D) heart rate. Values are mean (SEM).
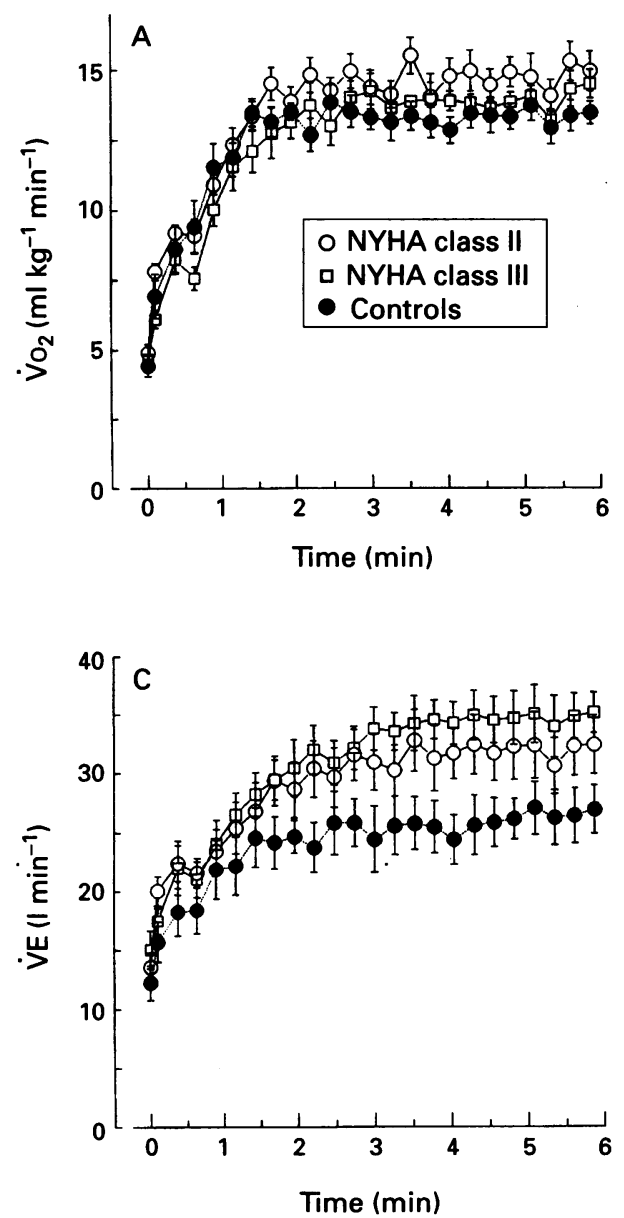

dent difference among the groups $(P<0.02)$, such that there was a trend towards lower values in the class III patients during the first two minutes, with a tendency to slightly higher values in both patient groups after three minutes of exercise. By contrast $\mathrm{VCO}_{2}$ was greater overall $(P<0.005)$ in both patient groups over the first six minutes, and there was a time dependent effect $(P<0.0001)$, so that the size of the between group difference became greater with time. The response of $\mathrm{VE}$ was similar to $\mathrm{VCO}_{2}$ with an overall increase in both patient groups $(P<0.05)$. The responses diverged with time $(P<0.0001)$. Heart rate was greater overall in patients $(P<$ 0.02 ), as was the rise over the first six minutes of exercise $(P<0.0001)$.

Table 2 shows the $\tau$ values for the exponential curves fitted to the plots of $\dot{\mathrm{VO}}_{2}, \dot{\mathrm{V}}_{2}$,
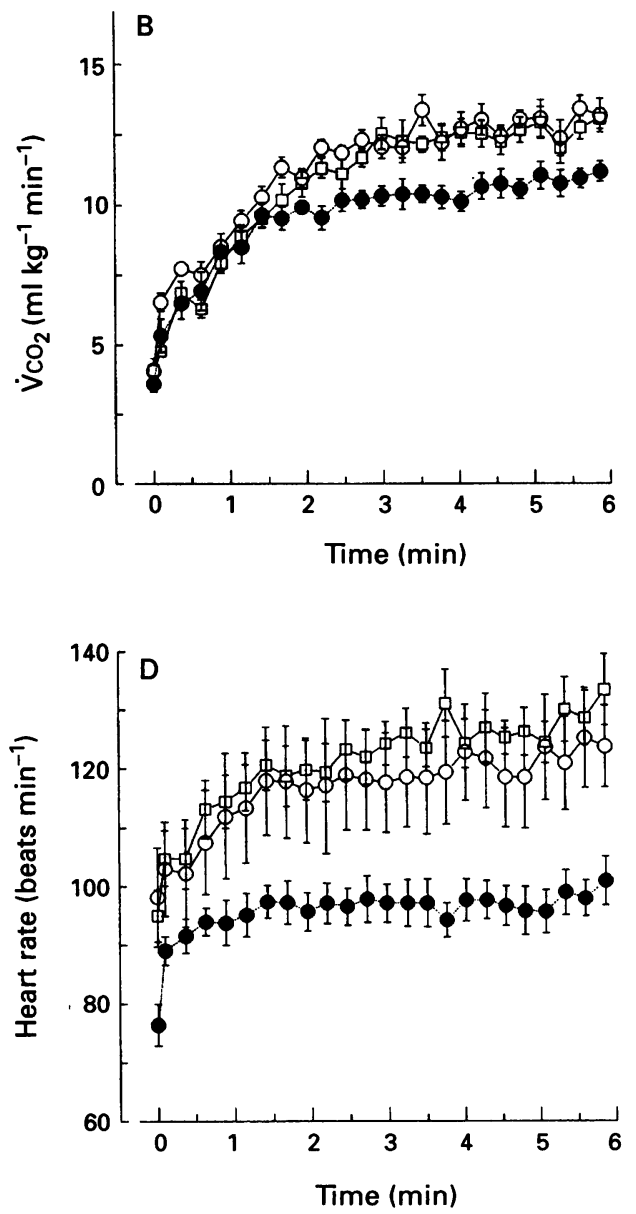
Table 2 Values for the time constants ( $\tau$ (min)) describing the rise in $\mathrm{VO}_{2}, \mathrm{VCO}_{2}, \mathrm{VE}$, and heart rate during the first six minutes of constant work rate exercise.

\begin{tabular}{|c|c|c|c|c|}
\hline & \multicolumn{2}{|l|}{ Patients } & \multirow[b]{2}{*}{ Controls } & \multirow{2}{*}{$\begin{array}{l}\text { Pvalue } \\
\text { (ANOVA) }\end{array}$} \\
\hline & NYHA class $I I$ & NYHA class III & & \\
\hline $\begin{array}{l}\mathrm{VO}_{2} \\
\mathrm{VCO}_{2} \\
\mathrm{VE} \\
\text { Heart rate }\end{array}$ & $\begin{array}{l}0.82(0.59 \text { to } 1.04)^{\star} \\
1.46(0.97 \text { to } 1.96) \\
1.59(0.89 \text { to } 2.30) \\
1.01(0.24 \text { to } 1.77)\end{array}$ & $\begin{array}{l}1.19(0.86 \text { to } 1.51)^{\star \star \star} \\
2.06(1.58 \text { to } 2.55)^{\star \star \star} \\
2.80(1.39 \text { to } 4.22)^{\star \star} \\
2.19(1.14 \text { to } 3.25)^{\star \star}\end{array}$ & $\begin{array}{l}0.49(0.35 \text { to } 0.64) \\
1.00(0.59 \text { to } 1.41) \\
0.95(0.60 \text { to } 1.30) \\
0.40(0.13 \text { to } 0.68)\end{array}$ & $\begin{array}{l}<0.0005 \\
<0.005 \\
<0.01 \\
<0.005\end{array}$ \\
\hline
\end{tabular}

Values are mean $(95 \% \mathrm{CI}) .{ }^{\star} \mathrm{P}<0.05 ;{ }^{\star \star} \mathrm{P}<0.01$; ${ }^{\star \star \star} \mathrm{P}<0.005$, Bonferroni correction, compared with controls.

$\dot{V E}$, and heart rate for the first six minutes of exercise. The model satisfactorily described the plots in all cases, as judged by visual inspection. Figure 2 shows representative plots of the $\dot{\mathrm{VO}}_{2}, \dot{\mathrm{V}} \mathrm{CO}_{2}, \dot{\mathrm{VE}}$, and heart rate responses and the corresponding fitted functions for a patient in class III and a control. In patients, especially those in class III, $\tau$ was longer for all variables, indicating a slower course towards the respective steady state values.

In patients as a whole, $\tau$ for $\mathrm{VO}_{2}$ was significantly correlated with peak $\mathrm{VO}_{2}$ (fig 3; $r=$ $0.73, \mathrm{P}<0.005$ ), but only showed a weakly positive, non-significant correlation with lactate at the end of exercise $(r=0.54, \mathrm{P}=$ 0.06 ). Analysis of covariance was carried out on the values of $\tau$ for $\mathrm{VO}_{2}$ with peak $\mathrm{VO}_{2}$ and lactate as covariates, and confirmed peak $\mathrm{VO}_{2}$ as the main determinant of $t$. Thus, the mean difference in $\tau$ between patients and controls
$(0.50(0.22-0.77) \mathrm{min})$ was eliminated $(0.00$ $(-0.37-0.37) \mathrm{min}$ ) when peak $\mathrm{Vo}_{2}$, but not when lactate $((0.33(0.03-0.64))$, was taken into account.

\section{Discussion}

The results of this study show that the $\dot{\mathrm{VO}}_{2}$ eventually reached by patients with chronic cardiac failure in response to a given absolute work rate is in fact not low when compared with that in normal controls. The time constant for the rise in $\dot{\mathrm{VO}}_{2}$ is longer in the patients, so that during early exercise the $\dot{\mathrm{Vo}}_{2}$ in the patient group tends to be lower than in the controls. This finding is likely to explain the paradox that $\dot{\mathrm{VO}}_{2}$ at similar absolute work rates may sometimes be significantly lower during incremental exercise tests in patients with chronic cardiac failure than in controls. ${ }^{1-4}$
Figure 2 Representative plots for rise in $(A) V O_{2}$ plots for rise in $(A) \mathrm{VO}_{2}$,
(B) $V \mathrm{CO}_{2},(C) \mathrm{VE}$, and (D) heart rate for the first six minutes of constant work rate exercise. The fitted exponential curves and their equations are also shown. The same men are used in all illustrations.
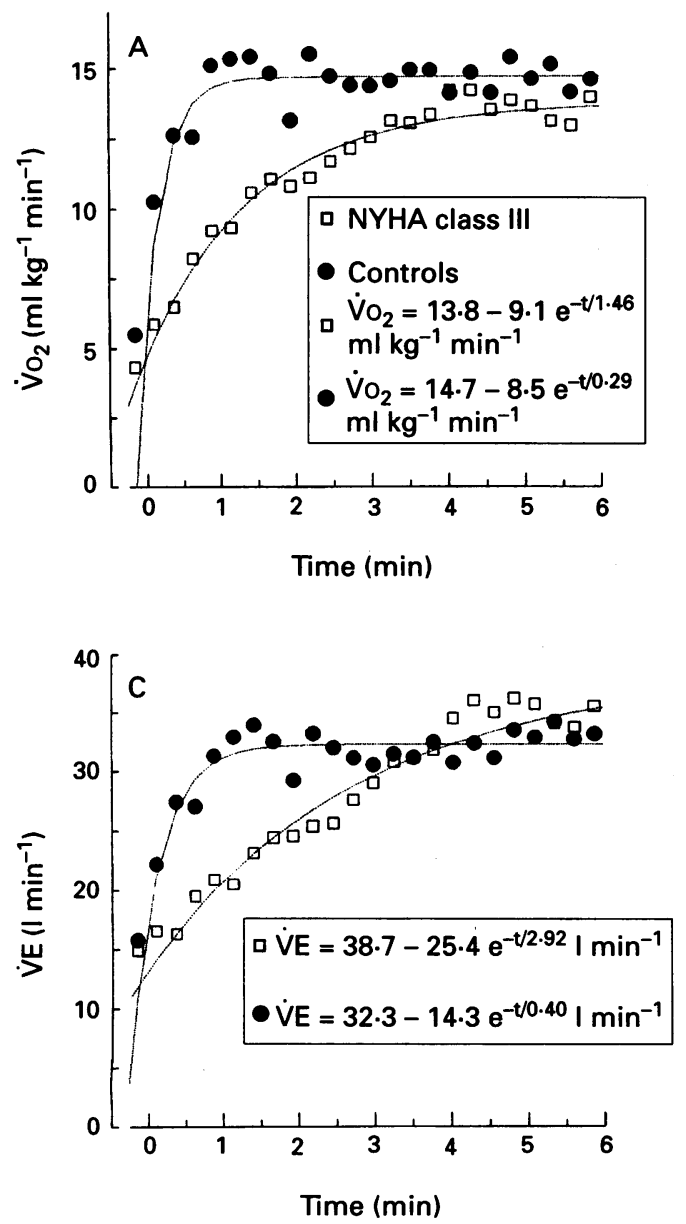
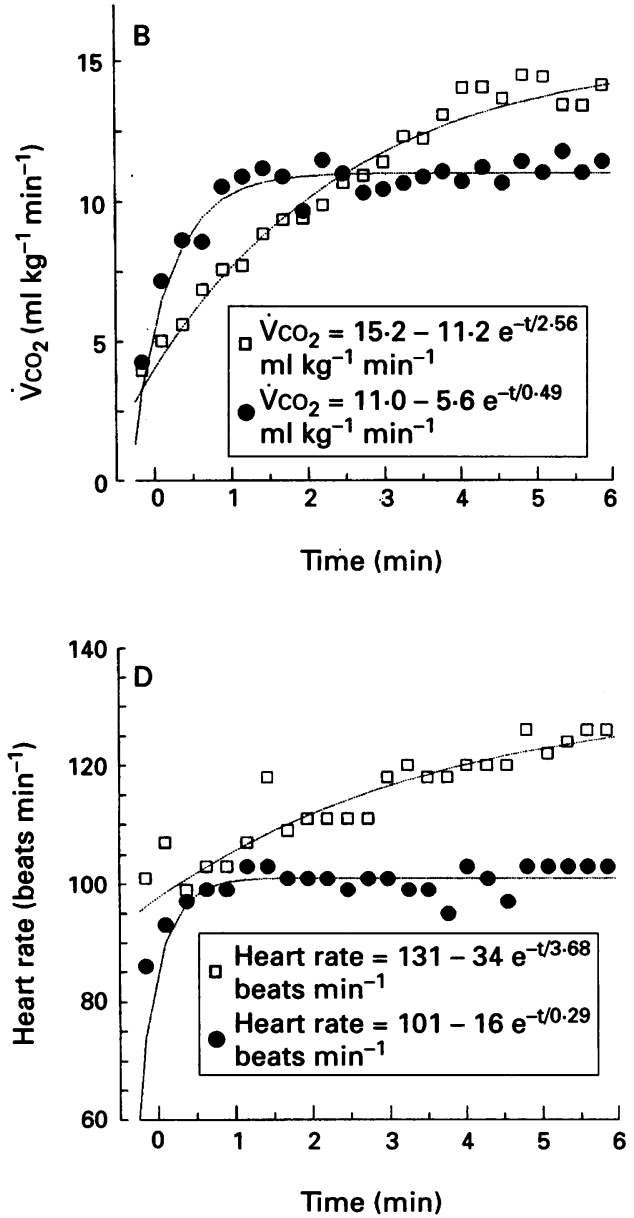
Figure 3 Time constants, $\tau$, for $\dot{V} \mathrm{O}_{2}$ plotted against $\tau$, for $\mathrm{V}_{2}$ plotted against
the peak $\mathrm{VO}_{2}$ reached. The regression line for the whole group is shown.

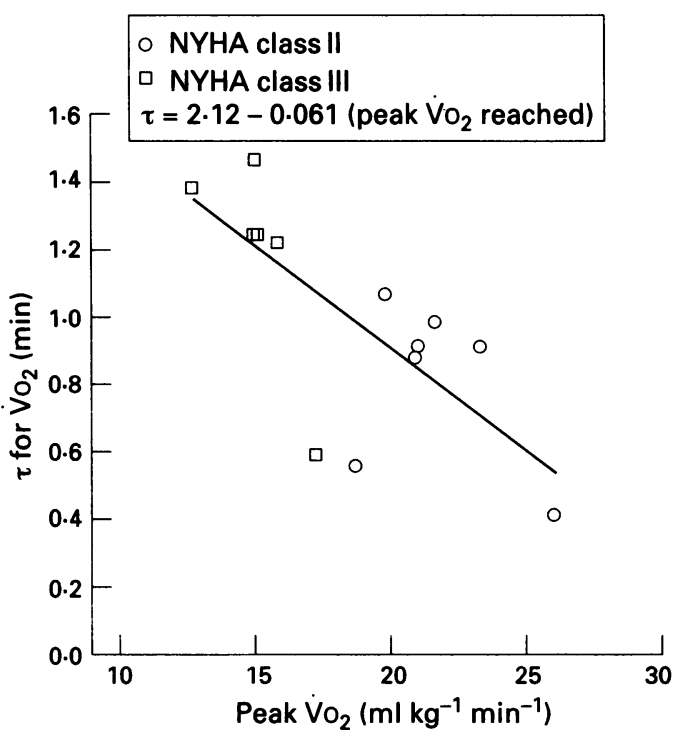

Differences in actual work, and hence $\dot{V}_{2}$, may occur between people performing the same apparent external work, especially on the treadmill. ${ }^{11}$ Factors such as stride length, ${ }^{12}$ or whether the bars are gripped may serve to vary the work done. In particular, patients with chronic cardiac failure take shorter strides than controls, which may lead to some increase in $\mathrm{VO}_{2}{ }^{13} \mathrm{We}$ attempted to minimise such variables by familiarisation, and by not allowing the bars to be gripped. Actual differences in external work rate are unlikely to be responsible for much of the difference in $\dot{\mathrm{VO}}_{2}$ between patients and controls, as the finding that $\dot{V O}_{2}$ in patients may be lower has also been noted in bicycle studies. ${ }^{414}$ These allow more accurate measurement of external work ${ }^{5}$ with lower variability of $\dot{\mathrm{V}}_{2}$ than treadmill studies. ${ }^{15}$ An advantage of treadmill over cycle ergometer exercise, however, is that the work done is related to the mass of the subject. This is important when comparing people of different weights, as in the current study, as work rate per $\mathrm{kg}$ is then standardised, and $\mathrm{VO}_{2}$ is expressed as a function of body weight.

Whereas we believe that all of our patients were adequately familiarised with the exercise testing procedures before the study, some of the controls had performed one less familiarisation test than the patients. On this basis, it could be argued that hyperventilation due to anxiety on the part of the controls contributed to their rapid gas exchange responses. This seems unlikely, however, as it is clear from inspection of figs 1 and 2 that neither $R$ nor the ratios $\dot{\mathrm{VE}} / \mathrm{VO}_{2}$ or $\dot{\mathrm{VE}} / \mathrm{VCO}_{2}$ increased excessively at any time during exercise. This implies that ventilation was appropriate to metabolic requirements.

Some investigators have found no difference in $\mathrm{VO}_{2}$ between patients with chronic cardiac failure and normal controls performing work of equal intensity. ${ }^{16}{ }^{17}$ As pointed out by Cowley et al, many of the patients in these studies had mild heart failure, and this may have masked any tendency to reduced levels of $\dot{\mathrm{VO}}_{2} .{ }^{3}$ In one study, $\dot{\mathrm{VO}}_{2}$ tended to be lower in patients with NYHA class III than class II, ${ }^{2}$ and other investigators noted a non-significant trend towards a lower $\nabla_{2}$ during submaximal exercise in patients with lower peak $\dot{V}_{2} \cdot{ }^{14}$ This is supported by our findings that patients with class III have longer values of $\tau$ than in patients with class II chronic cardiac failure, and that a strong inverse relation exists between peak $\dot{\mathrm{VO}}_{2}$ and the $\tau$ for $\dot{\mathrm{VO}}_{2}$.

The kinetics of $\mathrm{O}_{2}$ uptake have previously been found to be slowed in patients with chronic lung disease ${ }^{18}$ and pulmonary vascular disease, ${ }^{19}$ and also in controls given $\beta$ adrenoceptor antagonists. ${ }^{20}$ In addition healthy people exhibit faster $\mathrm{V}_{2}$ kinetics after training than before training. ${ }^{21} 22 \mathrm{~A}$ slow circulatory response to exercise is probably present in all of the above conditions. Our findings of slowed kinetics, not only of $\dot{\mathrm{VO}}_{2}$, but also of $\dot{\mathrm{V}} \mathrm{CO}_{2}, \dot{\mathrm{VE}}$, and in particular heart rate, in a disease characterised by an inadequate circulatory response to exercise, ${ }^{23}$ lend support to this suggestion. Moreover, in our study, analysis of covariance showed that the slowed kinetics for $\mathrm{VO}_{2}$ could be accounted for by differences in peak $\dot{V O}_{2}$, a measure of functional capacity highly dependent on cardiac output. ${ }^{24}$ This provides further evidence that an impaired circulatory response may be the factor responsible. Other factors linked to the deficient circulation, such as reduced ventilatory efficiency, ${ }^{25}$ may also contribute to delayed kinetics. Analogous delays in the return of $\dot{\mathrm{VO}}_{2}$ towards resting levels after exercise in chronic cardiac failure have recently been reported. ${ }^{26} 27$

The $\dot{V} \mathrm{CO}_{2}$, WE, $\mathrm{R}$, heart rate, venous lactate, and Borg score were all greater at the end of exercise in the patients with chronic cardiac failure than in the controls. This suggests that the exercise intensity constituted a greater physiological strain to the patient group. The inverse relation in patients between peak $\mathrm{VO}_{2}$ and both $R$ and lactate at the end of exercise is in line with this conclusion.

Lactic acid has long been known to be excessive in patients with cardiac failure when exercising at similar absolute work rates to controls, ${ }^{7829}$ and might be expected to be associated with a reduced $\dot{\mathrm{VO}}_{2}$. The energy supplied by anaerobic processes is, however, relatively small, and in view of the rather low lactate values at the end of exercise in our study, it is likely that anaerobic metabolism contributed much less than the $20 \%$ of total energy expenditure quoted for maximal exercise. ${ }^{30}$ Indeed, it is perhaps not surprising that the $\dot{V O}_{2}$ eventually reached by the patients and controls should be similar, as the increased lactate production in the patients may represent a $\mathrm{VO}_{2}$ not much greater than the error of $\dot{\mathrm{VO}}_{2}$ measurement (about $2 \%$ ). ${ }^{31}$ Furthermore, and more importantly in the patients, some of the deficit in $\mathrm{VO}_{2}$ arising during early exercise from anaerobic processes may be paid back later on. This, along with other as yet uncertain factors, ${ }^{32}$ may tend to cause excess $\mathrm{VO}_{2}$ during the latter stages of moderate to heavy exercise and may explain the tendency for $\mathrm{VO}_{2}$ 
to be greater later on in the exercise test in our patient groups. It has been proposed that lactate is causally associated with a drift upwards in $\dot{\mathrm{VO}}_{2}$ after three minutes of steady state exercise in both controls and patients with heart failure. ${ }^{33-35}$ We were unable to confirm a major association between the lactate at the end of exercise and the prolonged $\mathrm{VO}_{2}$ kinetics in our patients. Such conclusions must be treated with caution as we measured peripheral venous lactate concentrations that may be influenced by many factors including cardiac output, lactate washout from working muscle, and lactate metabolism by inactive muscle. ${ }^{36}$ It is also likely that $\dot{\mathrm{V}} \mathrm{CO}_{2}$ and $\dot{\mathrm{VE}}$ are affected by kinetics of lactate increase ${ }^{37}$ as well as by the direct influence of circulatory factors.

In conclusion, we have shown slowed kinetics for oxygen uptake and for other gas exchange variables and heart rate in response to exercise in patients with chronic cardiac failure. It is likely that circulatory factors are implicated, particularly the cardiac output response. These slowed kinetics are likely to explain the finding that $\mathrm{VO}_{2}$ is sometimes less in patients with chronic cardiac failure than in controls at equivalent work rates during incremental exercise.

We thank Sister E Crawford for her help with patient care throughout this study and to $S$ Green for help with the typescript.

1 Roberts JM, Sullivan M, Froelicher VF, Genter F, Myers J. Predicting oxygen consumption from treadmill testing in normal subjects and coronary artery disease patients. Am Heart $\mathcal{F}$ 1984;108:1454-60

2 Lipkin DP, Perrins J, Poole-Wilson PA. Respiratory gas exchange in the assessment of patients with left ventricular dysfunction. Br Heart $₹$ 1985;54:321-8.

3 Cowley AJ, Stainer K, Rowley JM, Hampton JR. Abnormalities of the peripheral circulation and respiratory function in patients with severe heart failure. $B r$ Heart $\mathcal{f} 1986 ; 55: 75-80$.

4 Cohen-Solal A, Chabernaud JM, Gourgon R. Comparison of oxygen uptake during bicycle exercise in patients with chronic heart failure and in normal subjects. $\mathcal{f} \mathrm{Am} \mathrm{Coll}$ Cardiol 1990;16:80-5.

5 Wasserman K, Hansen JE, Sue DY, Whipp BJ. Principles of exercise testing and interpretation. Philadelphia: Lea and Febiger, 1986.

6 Massie B, Conway M, Yonge R, Frostick S, Ledingham T, Sleight $\mathrm{P}$, et al. Skeletal muscle metabolism in patients with congestive heart failure: relation to clinical severity with congestive heart failure: relation to clinical

7 Meakins T, Long CNH. Oxygen consumption, oxygen debt and lactic acid in circulatory failure. $\mathcal{f}$ Clin Invest $1927 ; 4 \cdot 273-93$.

8 Elborn JS, Stanford CF, Nicholls DP. Reproducibility of cardiopulmonary parameters during exercise in patients with chronic cardiac failure. The need for a preliminary test. Eur Heart f 1990;11:75-81.

9 Borg GAV. Psychophysical bases for perceived exertion. Med Sci Sports Exerc 1982;14:377-81

10 Riley M, Elborn JS, McKane WR, Bell N, Stanford CF, Nicholls DP. Resting energy expenditure in chronic cardiac failure. Clin Sci 1991;80:633-9.

11 Bruce RA, Kusumi F, Hosmer D. Maximal oxygen uptake and nomographic assessment of functional aerobic impairment in cardiovascular disease. Am Heart $f$ 1973; 85:546-62.
12 Ralston HJ. Energy-speed relation and optimal speed during level walking. Int Zschr angew Physiol 1958;17:277-83.

13 Davies SW, Greig CA, Jordan SL, Grieve DW, Lipkin DP. Short-stepping gait in severe heart failure. $\mathrm{Br}$ Heart $\mathcal{f}$ 1992;68:469-72.

14 Wilson JR, Martin JL, Schwartz D, Ferraro N. Exercise intolerance in patients with chronic heart failure: role of improved skeletal muscle nutritive flow. Circulation 1984;69:1079-87.

15 Riley M, Northridge DB, Henderson E, Stanford CF, Nicholls DP, Dargie HJ. The use of an exponential protocol for bicycle and treadmill exercise testing in patients with chronic cardiac failure. Eur Heart $f$ 1992;13: with chron

16 Patterson JA, Naughton J, Pietras RJ, Gunnar RM Treadmill exercise in assessment of the functional capacity of patients with cardiac disease. Am $¥$ Cardiol ity of patients

17 Franciosa JA, Ziesche S, Wilen M. Functional capacity of patients with chronic left ventricular failure. $A m \mathcal{F} \mathrm{Med}$ 1979;67:460-6.

18 Nery LE, Wasserman K, Andrews JD, Huntsman DJ, Hansen JE, Whipp BJ. Ventilatory and gas exchange kinetics during exercise in chronic airways obstruction. $f$ Appl Physiol 1982;53:1594-602.

19 Sietsema KE. Oxygen uptake kinetics in response to exercise in patients with pulmonary vascular disease. $A m R e v$ Respir Dis 1992;145:1052-7.

20 Petersen ES, Whipp BJ, Davis JA, Huntsman DJ, Brown $H V$, Wasserman $K$. Effects of $\beta$-adrenergic blockade on ventilation and gas exchange during exercise in humans. f Appl Physiol 1983;54:1306-13.

21 Hagberg JM, Hickson RC, Ehsani AA, Holloszy JO. Faster adjustment to and recovery from submaximal exercise in the trained state. $\mathcal{F}$ Appl Physiol 1980;48:218-24.

22 Zhang Y-Y, Johnson MC, Chow N, Wasserman K. The role of fitness on $\mathrm{VO}_{2}$ and $\mathrm{VCO}_{2}$ kinetics in response to proportional step increases in work rate. Eur $\exists A P p l$ Physiol 1991;63:94-100.

23 Wood PW. Diseases of the heart and circulation. Philadelphia: Lippincott, 1956.

24 Weber KT, Kinasewitz GT, Janicki JS, Fishman AP Oxygen utilization and ventilation during exercise in patients with chronic heart failure Circulation 1982 65:1213-23

25 Sullivan MJ, Higginbotham MB, Cobb FR. Increased exercise ventilation in patients with chronic heart failure: intact ventilatory control despite hemodynamic and pulmonary abnormalities. Circulation 1988;77:552-9.

26 Hayashida W, Kumada T, Kohno F, Noda M, Ishikawa N, Kambayashi M, Kawai C. Post-exercise oxygen uptake kinetics in patients with left ventricular dysfunction. Int $\mathcal{F}$ Cardiol 1993;38:63-72.

27 Riley M, Stanford CF, Nicholls DP. Post-exercise ventilatory and heart rate responses in patients with chronic cardiac failure. Clin Sci (in press).

28 Cotes JE. The role of oxygen, carbon dioxide and lactic acid in the ventilatory response to exercise in patients with mitral stenosis. Clin Sci 1955;14:317-28.

29 Huckabee WE, Judson WE. The role of anaerobic metabolism in the performance of mild muscular work. I Relationship to oxygen consumption and cardiac output and the effect of congestive heart failure. $f$ Clin Invest 1958;37:1577-92

30 Ästrand P-O, Rodahl K. Textbook of work physiology. 3rd ed. New York: McGraw-HIIl, 1986.

$31 \mathrm{Katz} A$, Sahlin $\mathrm{K}$. Regulation of lactic acid production during exercise. $₹$ Appl Physiol 1988;65:509-18.

32 Poole DC, Schaffartzik W, Knight DR, Derion T, Kennedy B, Guy HJ, et al. Contribution of exercising legs to the slow component of oxygen uptake kinetics in legs to the slow component of oxygen uptak

33 Whipp BJ, Ward SA. Cardiopulmonary coupling during exercise. F Exp Biol 1982;100:175-93.

34 Roston WL, Whipp BJ, Davis JA, Cunningham DA, Effro RM, Wasserman $\mathrm{K}$. Oxygen uptake kinetics and lactate concentration during exercise in humans. Am Rev Respir Dis 1987;135:1080-4.

35 Zhang YY, Wasserman K, Sietsema KE, Ben-Dov I Barstow TJ, Mizumoto G, Sullivan CS. $\mathrm{O}_{2}$ uptake kinetics in response to exercise: a measure of tissue anaerobiosis in heart failure. Chest 1993;103:735-41.

36 Poortmans JR, Delescaille-Vanden Bossche J, Leclercq R. Lactate uptake by inactive forearm during progressive leg exercise. $¥ \mathrm{Appl}$ Physiol 1978;45:835-9.

37 Clode M, Campbell EJM. The relationship between gas exchange and changes in blood lactate concentration during exercise. Clin Sci 1969;37:263-72. 